http://dx.doi.org/10.18232/alhe.1111

Artículos

\title{
Teoria Marxista da Dependência e Superexploração da Força de Trabalho: história e debate atual na América Latina
}

\section{Marxist Theory of Dependence and Overexploitation of Workforce: history and current debate in Latin America}

\author{
Isaías A. de Moraes $1, *$ iD 0000-0003-1839-803X \\ Hugo M. V. de Almeida ${ }^{1}$ (D) 0000-0001-5453-6845
}

${ }^{1}$ Universidade Estadual Paulista, Araraquara, Brasil.

*Correspondencia: isaias.a.moraes@unesp.br

Resumo. O artigo lista como unidade de análise a Teoria Marxista da Dependência que surgiu na década de 1960 na América Latina e procura lançar luz sobre o passado, mas principalmente busca preencher algumas lacunas sobre sus contribuições, sobretudo em relação ao conceito de Superexploração da Força de Trabalho à economia contemporânea. Para atingir seu objetivo, utilizou-se da metodologia históricobibliográfica-analítica e estabeleceu-se como procedimentos técnicos a abordagem sistemática por meio da avaliação crítica dos dados bibliográficos sobre o assunto. O artigo está dividido em duas seções: na primeira seção, apresentou-se as principais leituras e proposições dos teóricos precursores da Teoria Marxista da Dependência; na segunda seção, o texto concentrou-se em demonstrar como esta teoria está renascendo na América Latina e como os estudos acercam da Superexploração da Força de Trabalho está se consolidando em interessante ferramenta de análise econômica.

Palavras-chave: Teoria Marxista da Dependência; pensamento econômico latino-americano; imperialismo econômico; Superexploração da Força de Trabalho; intercâmbio desigual.

CÓMO CITAR: Moraes, I. A. de e Almeida, H. M. V. de (2021). Teoria Marxista da Dependência e Superexploração da Força de Trabalho: história e debate atual na América Latina. América Latina en la Historia Económca, 21(1), 1-20. DOI:10.18232/alhe.1111 
Abstract. The article lists as a unit of analysis the Marxist Theory of Dependency that emerged in the 1960s in Latin America. This paper seeks to shed light on the past, but primarily to fill some gaps in the contributions of this theory, especially in relation to the concept of Overexploitation of the Workforce to the contemporary economy. To reach its objective, the article used the historical-bibliographic-analytical methodology and prioritized as technical procedures a systematic approach through the critical evaluation of the bibliographic data on the subject. The article is divided into two sections: the first section presents the main readings and propositions of the precursor theorists of the Marxist Theory of Dependency; in the second section, the text focused on presenting how this theory is being reborn in Latin America and how the studies on the Overexploitation of the Workforce are becoming in an interesting tool of economic analysis.

Key words: Marxist Theory of Dependency; Latin American economic thought; economic imperialism; overexploitation of the workforce; unequal exchange.

JEL: B14; B51; N36; N96; O54.

Recebido: 21 de agosto de 2019.

Aceito: 25 de outubro de 2019.

Publicado: 01 de setembro de 2020.

\section{INTRODUÇÃO}

A apreciação da Dependência como conceito econômico-político surgiu em meados da década de 1960 como crítica, sobretudo, à Teoria de Modernização de Walt Whitman Rostow em 1966, com suas etapas ao desenvolvimento econômico (Rostow, 1978); e ao pensamento nacionaldesenvolvimentista da Comissão Econômica para América Latina e Caribe (CEPAL), com sua proposta de Política de Substituição de Importações (PSI). Os estudos da Dependência têm seu berço na sociologia e ampliam-se para a economia e a política, não sendo obra de um intelectual solitário, mas trabalho coletivo de diversos autores. Isso faz com que haja "[...] trabalhos com níveis de desigualdades teórica, metodológica e empírica. Existem enfoques diferenciados e inclusive, em vários aspectos cruciais opostos" (Bambirra, 1985, p. 35). Pode-se afirmar, todavia, que os autores precursores de uma concepção da Dependência na economia e na política são: André Gunder Frank, Celso Furtado, Enzo Faletto, Fernando Henrique Cardoso, Osvaldo Sunkel, Ruy Mauro Marini, Theotonio dos Santos e Vânia Bambirra ${ }^{1}$ (Blomström e Hettne, 1984; Bresser-Pereira, 2016; Kay, 1989; Larrain, 1998; Palma, 1987).

A despeito da diversidade dentro das formulações, das interpretações e da construção teórica acerca da Dependência, depreende-se que, em geral, a operacionalização do conceito de dependência na economia e na política apregoa que:

O subdesenvolvimento não é uma fase prévia do desenvolvimento capitalista, mas produto necessário da expansão mundial do capitalismo mercantil europeu do século XVI. O desenvolvimento e o subdesenvolvimento, portanto, são aspectos diferentes, mas complementares do mesmo processo de expansão mundial do sistema capitalista.

\footnotetext{
${ }^{1}$ Alguns autores afirmam que houve uma primeira geração de estudos da Dependência na América Latina entre os anos de 1890-1920, quando o fenômeno da dependência foi percebido embrionariamente por intelectuais como José Martí, que apontaram a contradição entre a autonomia política e a dependência econômica, e por Jose Carlos Mariátegui, que analisou os limites da dependência, então sob o padrão de acumulação estabelecido pela hegemonia britânica, para industrializar a região (Kay, 1989; Martins, 2011).
} 
A estruturação do mercado em nível mundial dentro dos preceitos capitalistas fez com que houvesse uma relação de dependência entre a periferia e o centro dinâmico, que avança com seu capital explorando os periféricos, mantendo a condução do processo de acumulação e de expansão de capital. A exploração é reproduzida no interior dos países periféricos entre a burguesia dependente e a classe trabalhadora nas suas relações sociais, políticas, econômicas e culturais, inviabilizando, assim, as transformações e a superação do subdesenvolvimento.

As sociedades periféricas não são dualistas, ou seja, não houve na periferia o clássico conflito entre uma nova burguesia industrial e uma velha oligarquia arcaica, logo não havia e nem poderia haver uma burguesia nacional com capital forte capaz de conduzir a revolução democrático-burguesa como ocorreu na Europa e nos Estados Unidos da América (EUA). O que há nos países periféricos é uma burguesia dependente (Blomström e Hettne, 1984; Bresser-Pereira, 2016; Ouriques, 1994).

O termo Dependência, consequentemente, é aplicado à periferia do capitalismo em contrapartida ao do imperialismo, empregado ao centro do sistema. O imperialismo não se decorre mais de uma relação colonial, mas por hegemonia econômica. Os autores dos estudos da Dependência, com o passar do tempo, foram se consolidando e se aglutinando em três perspectivas: i) marxista; ii) dependente-associado e iii) estruturalista.

Os principais nomes da corrente marxista são: Adrián Sotelo Valencia, André Gunder Frank, Armand Mattelart, Carlos Eduardo Martins, Florestan Fernandes ${ }^{2}$ Franz Hinkelammert, Jaime Osorio, Marcelo Carcanholo, Orlando Caputo, Roberto Pizarro, Ruy Mauro Marini, Theotonio dos Santos e Vânia Bambirra. Essa visão é, com certeza, a que se constituiu em uma teoria consolidada da Dependência e seus intelectuais são denominados de Dependentistas. Os teóricos Dependentistas possuem alicerce (neo)marxista e, atualmente, estão atuando em correntes do Buen Vivir, Economia Solidária, Economia Social, Socialismo do século xxi, Bolivarianismo, Pensamento transmoderno, entre outros modelos ligados ou com influências de preceitos socialistas.

A perspectiva dependente-associado, embora utilize um campo semântico e conceitual marxista, não emprega uma metodologia baseada principalmente no materialismo histórico-dialético. Seus estudos ficaram radicalizados nas obras de Fernando Henrique Cardoso em parceria com Enzo Faletto e José Serra que apreciaram a Dependência a partir das relações entre o interno-externo e o estudo das estruturas de dominação e das formas de estratificação social interna. A corrente dependente-associado de Cardoso lançou mão, além da terminologia e de concepções marxistas, de instrumentos do funcionalismo de origem durkheimiano e do tipo-ideal weberiano para edificarem suas análises. O dependente-associado, na verdade, é uma Interpretação da Dependência que desataria, sobretudo com os estudos de Cardoso, na Terceira Via e no Liberalismo Social LatinoAmericano.

Por fim, a leitura estruturalista da Dependência tem como principais nomes Aldo Ferrer, Aníbal Pinto, Celso Furtado, Helio Jaguaribe, Ladislau Dowbor, Luiz Carlos Bresser-Pereira, Maria Conceição Tavares e Osvaldo Sunkel. Para os estruturalistas, há uma dominação-dependência

\footnotetext{
${ }^{2}$ Florestan Fernandes usava o termo dependência em seus textos desde a década de 1950, porém sem desenvolver uma Teoria ou Interpretação precisamente. O conceito ganha maior importância analítica na obra de Florestan no ensaio Sociedade de classes e subdesenvolvimento de 1967. Entretanto, em 1974, com a publicação de $A$ revolução burguesa, Florestan tornou-se mais ativo politicamente e radicalmente ancorado na Teoria Marxista, completando sua transição definitiva para esquerda marxista ao se identificar com o conceito de superexploração por isso resolvemos categorizá-lo como um dos teóricos marxistas que contribuíram para os estudos Dependentistas.
} 
entre centro-periferia, porém essa condição não é suficiente para explicar o subdesenvolvimento dos países periféricos. A Dependência é uma situação particular dos países cujos padrões de consumo foram modelados do exterior, mas ela pode ser mediada e alterada pelos efeitos de processos econômicos e sociais internos. A partir dessa concepção, é uma subárea de pesquisa da Teoria sobre o Desenvolvimento e o Subdesenvolvimento inserida no Estruturalismo-histórico da América Latina, no Novo Desenvolvimentismo, em setores do Social Desenvolvimentismo e, até mesmo, em correntes dentro do Buen Vivir, da Economia Social e Solidária e da Economia da Comunhão.

É diante dessa densidade histórica, interpretações, concepções e debate teórico sobre a Dependência que o presente artigo pretende realizar a revisitação da dimensão marxista a respeito. A perspectiva marxista da Dependência é a que se consolidou de fato como uma teoria e Escola de Pensamento Latino-Americana e seus autores elevados a Dependentistas. A interpretação dependente-associado eclipsou-se e a estruturalista nunca teve a intenção de se tornar em uma teoria, mas sempre operacionalizou o conceito de dependência visando sua instrumentalização como ferramenta necessária para compreender o subdesenvolvimento e para conceber o desenvolvimento.

Em vista disso, a realização de uma pesquisa que identifique a importância e as aplicações da Teoria Marxista da Dependência na economia, particularmente seus estudos sobre Superexploração da Força do Trabalho desde o seu surgimento na década de 1960 até a contemporaneidade, justifica-se e encontra-se relevância para melhor aproveitamento e conhecimento do impacto dessa teoria para a ciência econômica e como uma Escola de Pensamento autêntica latino-americano. Este trabalho, dessa maneira, procura lançar luzes sobre o passado, mas, primordialmente, preencher algumas lacunas sobre as contribuições da Teoria Marxista da Dependência para economia na contemporaneidade. A revisão dos principais estudos realizados sobre essa teoria possibilitou a inferência de que há excelentes textos que se dedicam aos percursores, porém há parcas pesquisas que tratam dos estudos contemporâneos.

Para atingir seu objetivo o artigo utilizou-se da metodologia histórico-bibliográfica-analítica, priorizando como procedimentos técnicos uma abordagem sistemática por meio da avaliação crítica dos dados bibliográficos sobre a temática. Com o escopo de explorar a contribuição da Teoria Marxista da Dependência desde seu surgimento na década de 1960 até a atualidade, o artigo privilegiou dar maior enfoque no conceito de Superexploração da Força de Trabalho por acreditar ser essa a ferramenta mais impactante apresentada pelos Dependentistas para os estudos da dinâmica centro-periferia na ciência econômica. A despeito desse recorte teórico-conceitual, o artigo não deixa de abordar outros temas relevantes para Teoria Marxista da Dependência, por exemplo imperialismo, subimperialismo, subcentro e intercâmbio desigual.

O artigo está dividido em duas seções. A primeira seção relata o arcabouço teórico da primeira geração de intelectuais da Teoria Marxista da Dependência. Na segunda seção, o texto apresenta as recentes contribuições realizadas pela segunda geração de Dependentistas. Nas duas seções deu-se maior enfoque ao conceito de Superexploração da Força de Trabalho em virtude de ser esse o campo com maior produção e contribuição da Teoria Marxista da Dependência para os estudos econômicos. Importante enfatizar que o texto não se restringiu a uma mera repetição do que foi dito ou escrito pelos principais teóricos, mas buscou investigar e minuciar o tema sob uma perspectiva que proporcione novas considerações e enfoques analíticos. 


\section{A TEORIA MARXISTA DA DEPENDÊNCIA: OS PREGURSORES}

Os precursores mais relevantes da corrente marxista da Superexploração são: André Gunder Frank, Orlando Caput, Roberto Pizarro, Ruy Mauro Marini, Theotonio dos Santos e Vânia Bambirra. O marco fundador da teoria da Dependência é o texto de André Gunder Frank intitulado Capitalismo y subdesarrollo em América Latina de 1965. Na obra, Gunder Frank enfatiza que o processo de desenvolvimento ou subdesenvolvimento nos países periféricos fazem parte do mesmo sistema de expansão do modo de produção do capitalismo como um todo, ou seja, as nações periféricas seriam dependentes de um processo maior de expansão do capitalismo mundial. Para Frank (1973): “[...] subdesenvolvimento não é nem original e nem tradicional e que nem o passado e nem o presente dos países subdesenvolvidos se parecem, em nenhum aspecto importante, ao passado dos países atualmente desenvolvidos. [...] são parte essencial da estrutura e desenvolvimento do sistema capitalista em escala mundial" (pp. 21-22).

Segundo Frank (1973), o que as políticas cepalinas e da Teoria de Modernização proporcionaram foi o desenvolvimento do subdesenvolvimento. Os países periféricos se desenvolveram relativamente, contudo sempre de forma complementar aos centrais por consequência de uma relação de dominação e de exploração via expropriação-apropriação monopolista do excedente econômico. Essa relação de exploradores e de explorados na extração do excedente econômico explica o desenvolvimento desigual tanto interno quanto externo nos países periféricos, bem como a própria construção da hierarquia nas relações interestados.

O desenvolvimento dos países periféricos, dessa maneira, é limitado pelo seu próprio status de capital dependente. Frank (1973) afirma que quando os países periféricos conseguem certa autonomia, por exemplo períodos das guerras mundiais e de crise econômica como 1929, eles alcançam maior crescimento econômico-industrial, pois as relações orgânicas de dependência com o capital oriundo dos países centrais ficam enfraquecidas.

O atual subdesenvolvimentismo da América Latina é o resultado de sua participação secular no processo de desenvolvimento mundial. [...] O subdesenvolvimento não é consequência da sobrevivência de instituições arcaicas ou da falta de capital nas regiões que se mantiveram isoladas da torrente histórica do mundo. Pelo contrário, o subdesenvolvimento tem sido e ainda é gerado pelo mesmo processo histórico que gera também o desenvolvimento econômico; o desenvolvimento do próprio capitalismo (Frank, 1973, pp. 24-26).

Apesar de a obra de Gunder Frank ser considerada como o marco inicial da Teoria Marxista da Dependência, foi somente com Ruy Mauro Marini em 1973 que a teoria ganhou um arcabouço de economia política marxista estruturada. Ruy Mauro Marini, em seu livro Dialética da Dependência de 1973, empenhou-se em edificar uma insólita Teoria Marxista da Dependência. Para tanto, segundo Marini a metodologia tem de ter:

A tarefa fundamental da Teoria Marxista da Dependência consiste em determinar a legalidade específica pela qual se rege a economia dependente. Isso supõe, desde logo, situar seu estudo no contexto mais amplo das leis de desenvolvimento do sistema em seu conjunto e definir os graus intermediários pelos quais essas leis se vão especificando. E assim que a simultaneidade da dependência e do desenvolvimento poderá ser entendida (Marini, 1973, p. 35). 
De acordo com Marini (1973), a inserção internacional da América Latina ocorreu nas estreitas relações da região com as metrópoles produtoras de manufaturados a partir do século Xvi. A América Latina era responsável por transferir um imenso volume de metais preciosos e de matériasprimas para Europa que se industrializava. Desse modo, os países periféricos sustentaram, em um primeiro momento, o desenvolvimento do capital comercial e bancário dos países europeus e, posteriormente, financiou a aflorante classe industrial da Europa ocidental, essencialmente da Grã-Bretanha, alicerçada nos ramos industriais voltados para a exportação dos putting-out system (sistemas manufatureiros domésticos) do século XVI e que se transformaria nas grandes indústrias da Europa.

A partir do século XIX ocorreu a independência política na América Latina, surgindo um grupo de países com as relações econômicas voltadas à Grã-Bretanha, a partir da mesma estrutura que vigorava no sistema colonial. Os países recém-criados ignoraram-se e passaram a organizar as suas economias para atender às necessidades inglesas, produzindo bens primários em troca de manufaturas de consumo e de capital externo. É a partir desse momento que ficou definida a inserção da América Latina na divisão internacional do trabalho de forma periférica e dependente (Marini, 1973).

Para Dos Santos (1978), “[...] a Dependência é uma situação na qual certo grupo de países têm sua economia condicionada pelo desenvolvimento e expansão de outra economia [...]” (p. 305). A Dependência, dessa maneira, "[...] está fundada numa divisão internacional do trabalho que permite o desenvolvimento industrial de alguns países e limita este mesmo desenvolvimento em outros" (p. 307).

A divisão internacional do trabalho tornou-se hierarquizada e constituída por blocos de poder que se articulam no interior dos Estados-nações, mas que pertencem a estruturas jurídicopolíticas distintas no centro e na periferia. Enquanto que no centro dinâmico do capitalismo há uma burguesia financeira-industrial, democrática e nacionalista controlando o bloco de poder que influencia o Estado-nação; na periferia há uma burguesia dependente, autoritária internamente, porém subordinada externamente, que aparelha, manipula e parasita o Estado, inviabilizando a construção de uma nação e de um projeto desenvolvimentista.

Verifica-se que o nexo da Dependência condiciona a estrutura interna nos países periféricos. As relações econômicas, sociais e políticas internas são redefinidas em função das possibilidades estruturais das distintas economias nacionais perante os centros de dominação mundial (Dos Santos, 1978). Os conflitos e as discórdias entre o bloco de poder dos países periférico-dependentes e do bloco de poder das nações centrais-autônomas não chegam a uma ruptura que permita a construção de um projeto nacional-desenvolvimentista e o catching-up dos países da América Latina. De acordo com Do Santos: "A Dependência, como se vê, não é uma relação de uma economia nacional autóctone com outra que a submete, mas sim uma relação básica que constitui e condiciona as próprias estruturas internas das regiões dominadas ou dependentes. [...]. É o caráter dessas forças internas que explica sua situação submissa, assim como sua capacidade de enfrentamento com os impulsos externos que a condicionam” (Dos Santos, 1978, pp. 313-314).

Para Marini (1973), a América Latina como região periférica-dependente tem a função na divisão internacional do trabalho: contrabalancear as tendências de queda da taxa de lucro nas economias desenvolvidas via redução do valor dos bens, de salários e do valor do capital constante mediante o aumento da exportação massiva de matéria-prima. A Dependência, desse modo, "[...] 
é uma relação de subordinação entre nações formalmente independentes, em cujo marco as relações de produção das nações subordinadas são modificadas ou recriadas para assegurar a reprodução ampliada da dependência” (Marini, 1973, p. 18).

Para Marini (1973), as relações comerciais internacionais são monopolizadas pelas economias industriais que dominam a produção e a diversificação dos bens industriais e de tecnologia, gerando um intercâmbio desigual. Uma parte do valor produzido na economia dependente não é apropriada nela, porquanto passa a integrar a dinâmica de acumulação de capital nas economias centrais, sustentando seu desenvolvimento econômico. O intercâmbio desigual entre os países do centro e da periferia faz com que haja queda da taxa de lucro ma periferia decorrente da diferença de valores entre as mercadorias exportadas e as importadas pela periferia.

O intercâmbio desigual e as relações de exploração internas nos países periféricos fazem com que seja estabelecido um mecanismo de compensação dessa perda de capital por parte dos capitalistas dependentes: superexploração do trabalho.

[...] o conceito de superexploração não é idêntico ao de mais-valia absoluta, já que inclui também uma modalidade de produção de mais-valia relativa - a que corresponde ao aumento da intensidade do trabalho. Por outra parte, a conversão do fundo de salário em fundo de acumulação de capital não representa rigorosamente uma forma de produção de mais-valia absoluta, posto que afeta simultaneamente os dois tempos de trabalho no interior da jornada de trabalho, e não somente o tempo de trabalho excedente, como ocorre com a mais-valia absoluta. Por tudo isso, a superexploração é melhor definida pela maior exploração da força física do trabalhador, em contraposição à exploração resultante do aumento de sua produtividade, e tende normalmente a se expressar no fato de que a força de trabalho se remunera abaixo de seu valor real (Marini, 2000, p. 159).

$\mathrm{O}$ aumento da intensidade do trabalho aparece, nesta perspectiva, como um aumento da mais-valia, conseguida através de uma maior exploração do trabalhador e não do incremento de sua capacidade produtiva. O mesmo se poderia dizer da prolongação da jornada de trabalho, isto é, do aumento da mais-valia absoluta em sua forma clássica. [...]. Dever-se-ia observar, finalmente, um terceiro procedimento, que consiste em reduzir o consumo do operário além de seu limite normal pelo qual 'o fundo necessário do operário se converte de fato, dentro de certos limites, em fundo de acumulação do capital', implicando assim um modo específico de aumentar o tempo de trabalho excedente. (Marini, 2000, pp. 124-125).

A superexploração do trabalho, segundo Marini (1973), é uma característica permanente dos países dependente e produz uma distribuição regressiva tanto da renda quanto da riqueza na economia, sendo responsável, de acordo com o autor, pela ruptura na circulação do capital entre a esfera da produção e a esfera de consumo das famílias. Para Marini (1979), os países periféricos não conseguem ter uma circulação de capital autônoma em virtude do desligamento do aparelho produtivo e a esfera da circulação, reproduzindo um capitalismo dependente e contraditório. $\mathrm{O}$ capitalismo dos países periféricos, neste caso América Latina, obedeceu a outro processo de amadurecimento e de reprodução de capital em razão de suas modalidades de integração ao mercado mundial capitalista. 
A economia exportadora é, portanto, algo mais que o produto de uma economia internacional fundada na especialização produtiva: é uma formação social baseada no modo capitalista de produção, que acentua até o limite as contradições que lhe são próprias. Ao fazê-lo, configura de maneira específica as relações de exploração em que se baseia e cria um ciclo de capital que tende a reproduzir em escala ampliada a dependência em que se encontra frente à economia internacional (Marini, 1973, p. 18).

Marini $(1973,1992)$ reconhece que por certo período houve sucesso no modelo nacionaldesenvolvimentista propalado pelos cepalinos, porém esse fracassou, pois não combatia a superexploração dos trabalhadores. O aumento da produtividade do trabalho, por causa da melhoria técnica, e a maior exploração do trabalhador permitem com que o capitalista mantém o valor unitário do produto e o seu valor social, obtendo a mais-valia extraordinária. Nesse sentido, economias como Brasil, México e Argentina passam a ser denominadas como economias industriais dependentes, uma vez que divergem da formação da economia industrial clássica; em que a concentração de capital e o trabalho assalariado promovem aumento da demanda pelo fato de o trabalhador tornar-se também consumidor. Em sua formação, a indústria dependente, pressionada pelos padrões da economia exportadora, não conseguiu criar um mercado interno consistente, ampliando-se a partir de modificações exógenas.

Na mesma linha de pensamento, Dos Santos (1978) reitera que a superexploração do trabalho estabelece um baixo nível de geração interna de forças produtivas e impõe limites à expansão do mercado interno. A dinâmica impede o ciclo de investimento e permite que o capital estrangeiro destine seus excedentes para outros rendimentos ou produções em países com ciclo mais dinâmico e intensos. Dos Santos (1972) também argumenta que a Dependência e a poupança externa geram déficits cambiais, impulsionando a queda da taxa de lucro dos capitalistas dependentes, pressionando a redução dos salários dos trabalhadores.

Percebe-se que enquanto os centros capitalistas tendem a desenvolver sua base tecnológica e industrial, baseando sua produção na mais-valia relativa; os países dependentes amparam seus padrões de acumulação na superexploração do trabalho. Dessa maneira, o capital forte de países centrais associado com a burguesia dependente dos países periféricos gera uma dinâmica de desenvolvimento do subdesenvolvimento graças a uma relação vertical do capital-trabalho. Essa dinâmica faz com que o gap entre a periferia e o centro sempre se mantém ou até mesmo aumente, impossibilitando o catching-up e a sofisticação produtiva da periferia.

A industrialização latino-americana corresponde assim a uma nova divisão internacional do trabalho, em cujo marco são transferidas para os países dependentes etapas inferiores da produção industrial (...) sendo reservadas para os centros imperialistas as etapas mais avançadas e o monopólio da tecnologia correspondente. Indo ainda mais longe, pode-se distinguir na economia internacional escalões, nos quais vão sendo recolocados não só os novos países industriais, mas também os mais antigos (Marini, 1973, p. 24).

De acordo com Marini (1973, 1979), a industrialização da América Latina e a manutenção da superexploração do trabalho instauraram uma contradição: produção em escala, mas mercado consumidor limitado. Para solucionar essa contradição, os capitalistas dependentes reproduzem os padrões das economias centrais exportadora de manufaturados, estabelecendo subcentros econô- 
micos e políticos de acumulação mundial. Para Marini (1992), os subcentros são países que conseguiram realizar uma acumulação significativa de capital, ainda que inferior à dos países centrais. Os subcentros possuem características de nações centrais e periféricas ao mesmo tempo, ocupando uma posição intermediária entre a relação centro e periferia. Para se categorizar como subcentro é necessário, de acordo com Marini (1992), um comportamento subimperialista, que se identifica pela exploração da periferia pela semiperiferia ${ }^{3}$

O subimperialismo corresponde à expressão perversa da diferenciação sofrida pela economia mundial, como resultado da internacionalização da acumulação capitalista, que contrapôs ao esquema simples da divisão do trabalho -cristalizado na relação centro-periferia, que preocupava a CEPAL- um sistema de relações muito mais complexo. Nele, a difusão da indústria manufatureira, elevando a composição orgânica média nacional do capital, isto é, a relação existente entre meios de produção e força de trabalho, dá lugar a Subcentros econômicos (e políticos), dotados de relativa autonomia, embora permaneçam subordinados à dinâmica global imposta pelos grandes centros (Marini, 1992, pp. 137-138).

O subimperialismo nos países dependentes oscila, então, dentro de uma certa margem de possibilidades estabelecida pela relação com os países centrais-imperialistas: quanto maior a subordinação política do subcentro ao imperialismo-central, o subimperialismo se restringe somente a dimensões econômicas; por outro lado, quanto maior a autonomia política do subcentro na integração tecnológica ao imperialismo, mais forte se constitui o subimperialismo como um projeto de autonomia produtiva para alterar o lugar do país na hierarquia de poder político e econômico mundial (Marini, 1992).

Evidencia-se que, para os autores da Teoria Marxista da Dependência, o nacional-desenvolvimentismo enganava-se ao adotar um reformismo incapaz de modificar a essência da Dependência na América Latina: a superexploração dos trabalhadores e a mais-valia extraordinária responsáveis pelo desacordo entre a estrutura produtiva e as necessidades de consumo das massas. O nacionaldesenvolvimentismo, ainda, segundo os Dependentistas, foi responsável por criar subcentros que repetiam a mesma lógica de exploração dos países centrais com Estados mais fracos, retroalimentando essa dinâmica exploratória do capitalismo. Para os precursores da Teoria Marxista da Dependência, por consequência, não haveria outro caminho para o desenvolvimento senão a imediata revolução socialista, sem a necessidade de passar pela chamada revolução democrático-burguesa. O socialismo seria o único meio capaz de superar a superexploração do trabalho, a desigualdade e o (sub)imperialismo.

A TEORIA MARXISTA DA DEPENDÊNCIA E SUPEREXPLORAÇÃO DA FORÇA DE TRABALHO: DEBATE ATUAL

Após anos de exílio por conta da ditadura militar no Brasil (1964-1985), os principais autores da Teoria Marxista da Dependência retornaram ao país diante de uma nova realidade. O cenário e a atmosfera latino-americana eram outros em meados da década de 1980 e começo de 1990, havia uma nova esquerda mais cultural e pós-moderna -novas pautas conquistaram maior protagonismo

\footnotetext{
${ }^{3}$ A relação Brasil-Paraguai, por exemplo, pode ser categorizada como um comportamento subimperialista brasileiro em relação ao país vizinho (Moraes e Vieira, 2015).
} 
no debate político-econômico como feminismo, ambientalismo, culturalismo, racismo, questão de gênero e orientação sexual, etc.- e havia o predomínio do pensamento da corrente dependenteassociado, agora transmutado para a Terceira Via e o Liberalismo Social latino-americano.

Em razão disso e do avanço da ortodoxia convencional na América Latina no final da década de 1980-90 com a agenda político-econômica orbitando em torno do Consenso de Washington, tendo como um dos grandes defensores no continente Fernando Henrique Cardoso -que afirmou em artigo assinado junto com José Serra de que era necessário lacrar às chaves as ideias da Teoria Marxista da Dependência- o pensamento de Bambirra, Dos Santos, Frank e Marini teve pouco espaço nos meios acadêmicos e partidários no final do século xx (Cardoso e Serra, 1978; Wasserman, 2017).

Tais contribuições, além de terem sido alvo da censura e da perseguição política, sofreram um sistemático trabalho de deturpação intelectual, no qual o ex-presidente e sociólogo Fernando Henrique Cardoso teve um papel central (...). No Brasil, foi se construindo uma espécie de 'pensamento único' sobre o tema da Dependência centrado em grande medida na perspectiva defendida por Cardoso, de tal modo que se firmou um relativo desconhecimento -e até mesmo deformação- das contribuições inscritas na tradição marxista, dentro da qual estariam inscritas as obras de Andre Gunder Frank, Theotônio dos Santos, Vânia Bambirra e, principalmente, Ruy Mauro Marini (Prado, 2010, p. 71, grifo no original).

Diante dessa conjuntura, Bambirra, Dos Santos e Marini tiveram dificuldades de reintegrar na vida acadêmica em um primeiro momento e seus estudos ficaram categorizados como datados a década de 1960-70. Politicamente, a Teoria Marxista da Dependência e seus autores vincularam ao Partido Democrático Trabalhista (PDT) e ao "[...] radicalismo político de Brizola, Darcy Ribeiro e outros pedetistas mais radicais em uma época em que a maior parte da esquerda se posicionava a favor da conciliação" (Wasserman, 2017, p. 181) em boa parte representado pelo novo-sindicalismo do Partido dos Trabalhadores (PT) com a liderança do líder sindical Luiz Inácio Lula da Silva. Todos esses fatores, além do falecimento de Marini em 1997, fizeram com que a Teoria Marxista da Dependência sofresse um hiato produtivo de décadas.

A realidade latino-americana e mundial passou por expressivas transformações desde quando surgiu a Teoria Marxista da Dependência na década de 1960. Contemporaneamente, não há mais a bipolaridade entre bloco capitalista verso bloco socialista, o capital financeiro expandiu-se a níveis inimagináveis, a economia totalmente planificada dos modelos socialistas marxistas entrou em colapso, houve inserção de novas periferias na divisão internacional do trabalho, surgiram blocos de livre-comércio, novas pautas e atores entraram na arena política; enfim, o mundo tornou-se mais globalizado, interligado e diversificado.

No entanto, a dicotomia Norte (países centrais) - Sul (países periféricos) predomina e até mesmo se acentua como demonstrou Piketty (2014). Isso fez com que pesquisadores latinoamericanos -formados no final da década de 1990 e começo dos anos 2000-desiludidos com os danos sociais e o fraco desempenho do modelo econômico do Liberalismo Social na América Latina -que foi incapaz de retirar a região da condição de dependência e de romper com o subdesenvolvimento- buscassem ferramentas originais para compreender a inserção das economias dependentes no sistema internacional. Com uma produção ativa até sua morte, com 81 anos em 2018, Dos Santos foi, com certeza, o maior responsável em formar novos quadros de intelectuais do pensamento Dependentista e em propagar suas ideias. 
Os principais nomes desta nova geração de autores da Teoria Marxista da Dependência com contribuições originais são: Adrián Sotelo Valencia, Carlos Eduardo Martins, Jaime Osorio e Marcelo Carcanholo. 4 A escolha desses autores não foi fortuita, mas foi condicionada com maior intensidade no caráter inovador e complementar de suas obras para o pensamento Dependentista latino-americano, não ficando seus estudos restritos a mera interpretação, estudo de caso ou descrição teórico-histórica. Esses autores estão revisitando os conceitos e os métodos desenvolvidos pelos precursores, sobretudo os estudos de Ruy Mauro Marini, e incorporando novas leituras, metodologias, além de temas contemporâneos como: economia sistema-mundo, integraçãocooperação regional e Sul-Sul, tecnologias, meio-ambiente, gênero, etc.

A segunda geração da Teoria Marxista da Dependência está realizando um resgate crítico dos estudos elaborados pelos precursores para compreender a inserção subordinada das economias dependentes no capitalismo contemporâneo. Os autores da segunda geração estão recuperando as principais teses da Teoria Marxista da Dependência, por exemplo: dinâmica centro-periferia como elementos contraditórios de uma mesma unidade dialética, o processo de acumulação de capital no capitalismo mundial, a descrição e a categorização dos condicionantes estruturais geradores da Dependência, a relação dialética da Dependência com as particularidades conjunturais, a formação de subcentros com o aumento do subimperialismo e a Superexploração da Força de Trabalho como motor central da acumulação de capital (Carcanholo, 2013).

Para os autores da segunda geração da Teoria Marxista da Dependência, a unidade dialética entre o desenvolvimento e o subdesenvolvimento permanece no sistema internacional apesar do avanço da globalização. O desenvolvimento econômico obtido pelas economias centrais é mantido pelo subdesenvolvimento das economias periféricas em um processo dialético necessário para o processo de expansão do capitalismo mundial. Para Carcanholo (2013), a categorização de economias subdesenvolvidas e economias desenvolvidas cria uma falsa sensação de trajetória do progresso com forte viés positivista e moralista. Os conceitos de desenvolvimento e de subdesenvolvimento, para o autor, seriam incapazes de explicar a dinâmica e a conjuntura das economias. É preciso, portanto, retomar o centro da análise para o conceito de Dependência.

A Dependência, assim, seria uma situação em que uma economia estaria condicionada pelo desenvolvimento e expansão de outra à qual está subordinada, o que se expressaria no fato de a economia dominante poder expandir-se autossustentadamente - de forma contraditória e dialética, como característico do capitalismo- enquanto a dependente só o faria como reflexo essa expansão, ou de forma constrangida pela situação de dependência, tendo efeitos positivos e negativos sobre o seu desenvolvimento (Carcanholo, 2013, pp. 193-194).

Carcanholo (2013) resgata e incorpora na Teoria Marxista da Dependência, ademais, o conceito de processualidade empregada por Marx, para esclarecer de melhor forma como se constrói a relação de dominação-dependência. Assim, a processualidade ajuda a descrever "[...] como de-

\footnotetext{
${ }^{4}$ Há, ainda, um grupo de pesquisadores muito ativo em debater acerca das contribuições e das limitações da Teoria Marxista da Dependência como: Agostina Costantino, Andrea Cecilia Haro, Angélica Lovatto, Ariel Slipak, Atilio Borón, Camila dos Santos, Claudio Katz, Emiliano López, Facundo Barrera, Facundo Lastra, Fernanda Beigel, Fernando Correa Prado, Francisco Cantamutto, Mariano Féliz, Mariano Treacy, Marina Machado, Marisa Silva Amaral, Nildo Ouriques, Raphael Seabra, Roberta Traspadini, Rodrigo Castelo, Rodrigo Franklin, Rolando Astarita, Paula Belloni e Plínio de Arruda Sampaio Jr.
} 
terminada estrutura social se desenrola com o passar do tempo, como as leis de funcionamento de determinada sociabilidade se manifestam em uma trajetória de tempo, manifestações essas que sempre possuem uma determinação histórica" (p. 193).

A processualidade, diferentemente do conceito de desenvolvimento, pressupõe a complexificação de todas as relações sociais e de seus modos de produção dialeticamente e respeitando uma densidade histórica. Para Carcanholo (2013), enquanto mais se alimenta o conceito de desenvolvimento econômico em detrimento do de processualidade mais se enraíza a unidade dialética entre o desenvolvimento e o subdesenvolvimento, perpetuando a cultura de Dependência na sociedade. Em vista disso, se os países periféricos desejam sair da condição de dependentes um dos primeiros passos é adotar o conceito de processualidade em substituição ao de desenvolvimento em suas leituras e discursos.

Para Carcanholo (2013) a Dependência ocorre, em suma, por conta do processo de intercâmbio desigual. O intercâmbio desigual é a transferência de parte da mais-valia produzida na economia dependente e apropriada pelas economias centrais. O intercâmbio desigual, para o autor, possui três mecanismos que o define:

- Apropriação/acumulação de mais-valia: economias que possuem capitais com produtividade abaixo da média mundial tendem a gerar mais valor do que são capazes de se apropriarem. $\mathrm{O}$ desnível na produtividade de mercadorias entre o capital forte dos países centrais e o capital débil dos países periféricos faz com que haja um mecanismo de apropriação/acumulação de mais-valia das economias dependentes para as centrais.

- Obtenção de lucro médio superior: economias que possuem composição orgânica do capital, isto é, produtividade acima da média das demais conseguem determinar um preço de venda maior. Isso permite com que os capitalistas dessas economias consigam se apropriar de muito mais valor do que produziram, gerando um lucro médio superior. Os capitalistas das economias dependentes não conseguem ter a mesma margem de lucro em virtude da baixa produtividade do capital.

- Sustentação de produção abaixo das demandas: o capital forte das nações centrais consegue manter maior grau de monopólio sobre seus mercados específicos, possibilitando com que inflacione os preços dos produtos fornecidos para países periféricos via produção abaixo da demanda. Isso faz com que os preços de mercado fiquem acima dos preços de produção, criando uma massa de valor apropriado maior do que foi produzido por esses capitais (Carcanholo, 2013, p. 195).

Esses três mecanismos que proporcionam o intercâmbio desigual geram uma condição estrutural de Dependência obrigando os capitalistas dos países periféricos a procurarem outros meios para compensarem de algum modo suas perdas de lucratividade. O principal mecanismo encontrado pelos capitalistas dependentes é a superexploração do trabalho. Não é por acaso que a maior contribuição dos autores da segunda geração da Teoria Marxista da Dependência está centrada na compreensão desse mecanismo, consequentemente o foco dessa seção é no conceito de Superexploração da Força de Trabalho.

Carcanholo (2013) operacionaliza de forma mais precisa o conceito desenvolvido por Marini na década de 1970. Marini (1973) utiliza superexploração do trabalho, porém Carcanholo (2013) demonstra que dentro do arcabouço teórico de Marx, o ideal é a operacionalização conceitual enfatizando que a superexploração é da força de trabalho. Para o autor: 
Como toda e qualquer mercadoria, a força de trabalho é uma unidade dialética entre seu valor de uso e seu valor. Esse último equivale ao tempo de trabalho socialmente necessário para produzir e reproduzir a capacidade de trabalho, de acordo com determinações sociais e históricas. Assumir a troca de equivalentes significa assumir que os salários pagos correspondem a esse valor da força de trabalho. [...] A Superexploração da Força de Trabalho [...] trata de uma categoria que não pode ser confundida com as distintas formas que existem no capitalismo para elevar a taxa de mais-valia (taxa de exploração) [...] a Superexploração da Força de Trabalho é uma categoria específica da economia dependente, portanto em um menor nível de abstração do que as leis gerais do modo de produção capitalista [...] (Carcanholo, 2013, pp. 198-199).

De acordo Carcanholo (2013), a Superexploração da Força de Trabalho, portanto, ocorre somente nas economias dependentes como um mecanismo de compensação das perdas ocasionadas por efeito do intercâmbio desigual entre os capitalistas dependentes (países periféricos) e os capitalistas autônomos (países centrais). A Superexploração da Força de Trabalho seria a forma encontrada pelo capitalista dependente de dinamizar sua produção e o modo da própria economia da periferia se desenvolver. O enfoque de que a superexploração é na força de trabalho é sensata para diferenciar de outros mecanismos utilizados para explorar o trabalhador no sistema capitalista, como precarização do trabalho.

Jaime Osorio $(2016,2018)$ faz uma importante contribuição na melhor delimitação conceitual e da compreensão do processo de funcionamento da Superexploração da Força de Trabalho. Para Osorio $(2016,2018)$, não se pode confundir o conceito de Superexploração da Força de Trabalho com o de pobreza absoluta. A existência de remuneração abaixo do valor da força de trabalho faz com que a alocação monetária por parte do trabalho fique limitada, mas não inexistente. $\mathrm{O}$ consumo, inclusive, pode incrementar em bens produzidos por países centrais, como mercadorias tecnológicas com maior sofisticação em razão da pressão conjuntural e estrutural, mas outros bens e serviços terão consumo deficiente, por exemplo, itens de saúde, lazer e cultura. Isso depende das necessidades e condições histórico-sociais prevalecentes das economias dependentes. A Superexploração da Força de Trabalho faz com que haja incremento da pobreza relativa, mas não é sinônimo de pauperização ou de exploração.

Diferentemente de Carcanholo (2013) -que pressupõe a existência da Superexploração da Força de Trabalho somente nas economias dependentes-, Martins (2018) defende que a situação monopolista da economia mundial contemporânea faça com que o valor de mercado e o valor individual dos capitais de composição superior se aproximem, levando com que haja Superexploração da Força de Trabalho também nas economias centrais. Para Martins (2013), a financeirização, as cadeias globais de valor forçaram uma nova divisão internacional do trabalho, resultando com que a Superexploração da Força de Trabalho não ficasse mais restrito somente aos países periféricos.

De acordo com Martins (2013), atualmente, a concentração e a centralização do capital sob os trabalhadores estão avançando. Isso leva a um novo patamar na composição técnica dos monopólios. A expressão dessa tendência é o aumento da desigualdade e a estagnação dos salários nos EUA e na Europa Ocidental. O alto nível de centralização e de concentração de capital se expressa nos menores impactos dos ciclos de influxo de capital estrangeiro para o desenvolvimento do capitalismo dependente. 
A Superexploração da Força de Trabalho, para Martins (2018), deve tomar como primeiro indicador a queda sistemática dos preços da força de trabalho em relação a seu valor médio na economia mundial. A Superexploração da Força de Trabalho, segundo o autor, não se restringe apenas pelo desvio da força de trabalho em relação a seu valor, mas, também, pelo emprego da maior exploração que os determinam em função das transferências de valor. A queda das taxas de mais-valia imposta pela estrutura e pela conjuntura internacional e nacional fez com que os capitais de composição média e inferior recorressem a maior exploração da força de trabalho. Consequentemente, há uma queda de preços da força de trabalho em relação aos estabelecidos em condições médias de produção em âmbito nacional.

Para Marini (1973), a impossibilidade do capital débil de aumentar sua taxa de acumulação via mais-valia relativa ou outro mecanismo faz com que haja somente uma saída para o capitalista dependente: a Superexploração da Força de Trabalho, que acontece sempre que a apropriação de mais-valia de um capital por outro não puder ser compensada pela expansão de mais-valia relativa (geração endógena de tecnologia) pelo capital expropriado. Contudo, Martins (2018) demonstra que Marini (1973) equivocou-se ao empregar o conceito de força de trabalho exclusivamente em nível nacional, desarticulando-o de seu eixo de referência mundial.

Tal erro analítico, segundo Martins (2018), fez com que a queda dos preços de força de trabalho em uma economia dependente não estivesse atrelada ao valor médio da força de trabalho mundial. Marini (1973), então, afirmava que a mais-valia relativa (geração endógena de tecnologia) seria incompatível com a Superexploração da Força de Trabalho, pois essa inviabilizaria o trânsito de mais-valia relativa como forma predominante das relações entre capital e trabalho. Para Martins (2018), a Superexploração da Força de Trabalho limita, significativamente, o mais-valor relativo, mas não necessariamente o bloqueia. Assim, envolve variadas dimensões e padrões distintos de reprodução do capital.

Além disso, Martins $(2017,2018)$ tem se dedicado à criação de um modelo para medir a Superexploração da Força de Trabalho intersetorial e intra-setorial. Para Martins (2017, pp. 3940), as transferências de mais-valia intersetorial podem ser analisadas de acordo com o seguinte modelo:

$$
\begin{gathered}
c+\frac{v}{w}+m=P b I \\
c+\frac{v}{w}+m=P b I \\
c+\frac{v}{x}+m-z=P a I
\end{gathered}
$$

Considerando que: $c=$ capital constante; $v=$ capital variável; $w=$ variação da produtividade média dos setores de bens de consumo suntuários e maquinarias e equipamentos em relação aos bens de consumo necessários; $m$ = massa de mais-valia, acrescentada de sua variação; PbI = valor 
do produto do setor de bens de consumo suntuários; $\mathrm{x}$ = variação da produtividade média do setor de bens de consumo necessários; $m$ = massa de mais-valia, acrescentada de sua variação; $z=$ impacto da economia de capital variável na mais-valia, a parir do diferencial de progresso técnico nos setores que produzem direta ou indiretamente bens consumo suntuários; e PaI = valor do produto do setor e de bens de consumo necessários.

Se, para aumentar a produtividade, houver um aumento na composição orgânica do capital, haverá uma queda na taxa de lucro no setor dos produtos de consumo necessários. Portanto, quanto maior for o peso do setor de bens de consumo suntuários adicionado o setor das máquinas e de equipamentos, os diferenciais de produtividade a seu favor e a composição orgânica do capital, maior será a restrição à mais-valia relativa em virtude dos efeitos sobre a taxa de lucro no setor de bens de consumo necessários.

Para tentar mensurar quando ocorre a Superexploração da Força de Trabalho intrasetorialmente, Martins (2018, pp. 474-475) apresenta o seguinte modelo:

$$
\begin{gathered}
c+v+m=P \\
c+\frac{V}{X}+m=\frac{p \cdot y}{z} \\
c+\frac{v}{x}+m=\frac{p \cdot y}{x}
\end{gathered}
$$

Considerando que: $c=$ capital constante; $V / v=$ capital variável; $X / x=$ desvalorização das mercadorias que representam os bens de consumo necessário, a qual é superior à variação de sua produtividade, implicando queda do preço abaixo do valor; $\mathrm{m}=$ mais-valia; $P / p=$ valor do produto; $y=$ variação da produtividade do capital de composição técnica inferior; e $z=$ desvalorização média das mercadorias no setor de bens de consumo suntuários, que é inferior à varia de sua produtividade, implicando elevação do preço acima do valor.

Levando em consideração que cada mercadoria do setor de bens de consumo necessário representa a média daqueles que o compõem quanto ao valor e à produtividade; e levando em consideração que tal suposição seja extensiva às mercadorias do setor de bens de consumo suntuário tem-se a heterogeneidade tecnológica e a atuação da mais-valia extraordinária, dentro e entre os ramos ou setores produtivos. Isso pode levar ao bloqueio da mais-valia relativa nos capitais de composição tecnicamente inferior, mesmo na vigência da elevação de sua produtividade. Se esses capitais empregarem a maior parte da força de trabalho de uma formação social, estará instituída uma situação de prevalência da Superexploração da Força de Trabalho que restringirá ou abolirá a mais-valia relativa, como resultado das transferências de valor que sofrem (Martins, 2018, p. 475). 
Além de trabalhar na edificação de modelos ${ }^{5} \operatorname{com}$ a intenção de mensurar matematicamente a Superexploração da Força de Trabalho, Martins (2018) elenca sete critérios para compreender esse mesmo conceito. São eles:

- A Superexploração da Força de Trabalho deve ser entendida como a queda dos preços da força de trabalho em relação ao seu valor médio na economia mundial.

- O valor médio da força de trabalho pode ser determinado como aquele que se estabelece nas condições médias de produtividades e intensidade de trabalho ou como síntese das múltiplas particularidades do valor da força de trabalho.

- A Superexploração da Força de Trabalho para ser uma dimensão interna de uma formação social precisa contar com alto nível de heterogeneidade tecnológica e transferência de valor em benefício das empresas ou setores monopólicos.

- A prevalência de Superexploração da Força de Trabalho amplia-se quando o valor de mercado está significativamente abaixo das condições médias de produção.

- A situação monopolista da economia mundial faz com que o valor de mercado e o valor individual dos capitais de composição superior se aproximem, fazendo com que haja Superexploração da Força de Trabalho também nos países centrais.

- O estabelecimento da mais-valia relativa pela via da produtividade não é necessariamente incompatível com a Superexploração da Força de Trabalho.

- A Superexploração da Força de Trabalho é uma ferramenta capaz de compreender restrições ao consumo de uma sociedade, prolongamento de jornadas dos trabalhadores acima da média mundial ou na elevação da intensidade produtiva sem aumento de melhoramento tecnológico (Martins, 2017, pp. 41-42).

Assim como Martins $(2017,2018)$, Jaime Osorio $(2016,2018)$ afirma que a Superexploração da Força de Trabalho se ampliou para as economias centrais também, sobretudo pós-crise econômica de 2008. A Superexploração da Força de Trabalho mantém-se e amplia-se na era da mundialização-globalização em razão de uma expressiva massa de população semiativa e inativa, ou flutuante, latente e intermitente; sempre disponível para as necessidades e tempo do capital. Isso faz com que ocorra uma contradição no capitalismo uma vez que o avanço tecnológico determina com que haja aumento do valor dos bens que se incorporam a cesta dos bens-salário, no entanto, ao mesmo momento, há uma elevação inferior do valor da força de trabalho em relação ao valor do produto (Osorio, 2016).

A Superexploração da Força de Trabalho não resulta necessariamente na redução da demanda por parte do trabalhador, mas é um mecanismo para compensar as transferências de valores entre periferia-centro. Nas palavras de Osorio (2016): “[...] a tendência é que aumente a massa de bens necessários (leite, pão, ovos, carne, feijão, roupas) e sociais (refrigeradores, celulares, rádio, televisão, cinema, educação, ócio, etc.), mas que, ao mesmo tempo, tal aumento não se expresse

\footnotetext{
${ }^{5}$ A compreensão textual ou a aplicabilidade dos modelos aqui apresentados não é o objetivo do artigo que tem um caráter mais bibliográfico-histórico, além de que tal excursão acadêmica é impossibilitada, neste momento, em virtude da limitação de espaço. Os modelos podem ser mais bem compreendidos e avaliados em Martins $(2017,2018)$.
} 
em uma elevação similar em termos do valor da força de trabalho e, portanto, em uma elevação igualmente similar dos salários. A massa de bens-salário aumenta mais do que o aumento do seu valor total" (p. 512).

Adrián Sotelo Valencia (2008, 2009), por sua vez, interpreta a Superexploração da Força de Trabalho de forma mais ampla que os demais teóricos Dependentistas: é a "[...] intensificação do trabalho, o aumento da jornada laboral e expropriação de parte do consumo do operário por parte do capital [...] independente que se viole ou não a lei do valor" (Valencia, 2008, p. 152). Para Valencia (2008), a Superexploração da Força de Trabalho, também, foi reproduzida pelas burguesias das economias centrais como forma de compensar as perdas em consequência da competição mais intensa e de maior homogeneização do capital por causa da mundialização-globalização.

Conquanto a maioria dos autores da segunda geração da Teoria Marxista da Dependência concorda que haja Superexploração da Força de Trabalho nas economias centrais atualmente, esse mecanismo ainda não se constituiu como eixo dinamizador e estruturante da economia nos países desenvolvidos como é nos países periféricos. Em outras palavras, na periferia a Superexploração da Força de Trabalho atua como elemento estrutural determinante da acumulação de capital e explica o próprio funcionamento do capitalismo dependente. Conforme Osorio (2016): "É um elemento que tem consequências decisivas para a reprodução do capital e nas formas de inserção das economias latino-americanas no sistema mundial" (p. 513).

O fenômeno da proliferação da Superexploração da Força de Trabalho nos países centrais, que se intensificou significativamente pós-crise 2008, é determinante para a sobrevivência do próprio sistema capitalista e seu modo de exploração. Salienta-se, todavia, que tal movimento não extingue as relações estruturais entre economias dependentes e centros imperialistas, mas convivem e se beneficiam delas. As economias centrais continuam capazes de produzirem mais-valia relativa em grande escala visto que possuem maior sofisticação produtiva, as economias periféricas prosseguem dependentes dessa estrutura produtiva e com dificuldades em gerar mais-valia relativa, sobrando, para a burguesia dependente, predominantemente o mecanismo de Superexploração da Força de Trabalho para obtenção de lucro (Valencia, 2008, 2009, 2016).

A diferença substancial em ambos 'tipos' ou modalidades de capitalismo consiste em que nos países dependentes a superexploração funciona sob a égide de processos e de trabalho fundados na mais-valia absoluta, na intensificação do trabalho e, por último, na redução de consumo do trabalhador. No capitalismo avançado, ao contrário, a superexploração se circunscreve aos ciclos dominantes do capital -que funcionam em termos regionais e internacionais - sob a hegemonia da mais-valia relativa, o incessante aumento da capacidade produtiva do trabalho, a aplicação da ciência e da tecnologia aos processos produtivos e de trabalho e, por último, em função dos processo interno dos mercados de consumo que exigem certo poder de compra das classes trabalhadoras para dinamizá-los, ainda que em muitas frações delas os níveis salarias estão sendo reduzidos, engendrando populações trabalhadoras de baixos salários, pobres, precárias, polivalentes com baixo poder de compra e acesso limitado para adquirir os meios de consumo básicos para a vida (Valencia, 2008, p. 46).

Os autores da segunda geração da Teoria Marxista da Dependência estão realizando, ademais, um esforço para aproximar seus preceitos dos estudos da Economia Política do Sistema-Mundo por meio de análises dos novos padrões de acumulação da economia mundial contemporânea e do 
capitalismo dependente. Especialmente, Martins, Osório e Adrián Sotelo estão dialogando com Beverly Silver, Giovanni Arrighi e Immanuel Wallerstein para construir uma Teoria Marxista do Sistema-Mundo e para um enfoque de longa duração da economia política da Dependência. Essa abordagem sobre o processo de acumulação de capital e o imperialismo na era da mundializaçãoglobalização pela Teoria Marxista da Dependência será apresentado em outro trabalho.

\section{ConsideraÇões Finais}

O presente artigo teve um objetivo singelo, o de explorar a contribuição da Teoria Marxista da Dependência, particularmente o conceito de Superexploração da Força de Trabalho. Para atingir este escopo a pesquisa optou em delimitar sua análise para os autores dessa teoria com trabalhos que envolvessem temáticas voltadas para economia em vez da política ou sociologia. Isso requereu um trabalho árduo de leitura, pois a Teoria Marxista da Dependência tem sua nascença na sociologia, dessa maneira os preceitos econômicos estão diluídos em textos acerca da política, da sociologia e das relações internacionais. Aliás, esse caráter transdisciplinar é uma das características que torna a Teoria Marxista da Dependência tão complexa e útil para compreender a formação econômica dos países periféricos e o atual cenário mundial de perpetuação da relação dominação-dependência. A Teoria Marxista da Dependência busca a superação da epistemologia positivista que parcela o campo de conhecimento como a própria realidade estudada.

Na primeira seção, verificou-se que a Teoria Marxista da Dependência tem sua centralidade de análise na dinâmica do capital e não centrada no conceito de Estado-nação ou na sociedade. Para Teoria Marxista da Dependência, o sistema internacional possui países com desenvolvimento desigual e combinado por força das leis de funcionamento do capital em distintas partes do mundo. Evidenciou-se, ainda, que metodologicamente, a teoria pauta-se em leis próprias do modo de produção capitalista em regiões dependentes - rejeitando as leis universais e naturais do mercado apregoados pela ortodoxia convencional- e preocupou-se em produzir conteúdo empírico da Dependência, investigando os aspectos socioeconômicos concretos dos países periféricos. Entretanto, seus conceitos e métodos sofriam as críticas de que eram formulações intuitivas e abstratas. O que não deixa de ser parcialmente verdadeiro.

Tal fato, contudo, foi se alterando à medida que a Teoria Marxista da Dependência começou a ganhar um arcabouço da Economia Política Marxista. Os estudos na questão da Superexploração da Força de Trabalho podem ser considerados o turning point da teoria da Dependência. É a partir desse momento que essa teoria conseguiu definir com precisão uma análise complexa sobre a integração da América Latina com o mercado mundial, estabeleceu categorias de análises sobre o capitalismo dependente, suas leis de gestação e de reprodução e sua influência na formação econômica e nas relações sociais dos países periféricos.

Em virtude disso, na segunda seção, buscou-se explorar mais o conceito de Superexploração da Força de Trabalho. A seção, dessa maneira, trouxe novos autores que estão contribuindo para a construção de um campo teórico econômico metodologicamente estruturado e com operacionalização conceitual expressivo. A segunda geração da Teoria Marxista da Dependência tem se esforçado em comprovar as leis específicas do capitalismo dependente, particularmente, o mecanismo de Superexploração da Força de Trabalho, inclusive procurando criar modelos econômicos para testá-las e não ficando somente restritos à retórica. Os modelos podem ser discutíveis (e devem), pois somente assim haverá avanço no pensamento Dependentista. 
Por fim, o que se destaca na Teoria Marxista da Dependência é sua originalidade e peculiaridade nas ciências humanas e sociais aplicadas. Apesar da teoria se enquadrar dentro de um pensamento e tradição filosófica e analítico-metodológica marxista, ela conseguiu apresentar uma visão singular e distinta das economias do hemisfério sul para a compreensão da dinâmica internacional. Os autores intentaram explicar o desenvolvimento do capitalismo na periferia e da periferia, isto é, fizeram uma leitura fora do que era vigente dos grandes centros da Europa e dos EUA, contribuindo expressivamente para a tradição do pensamento marxista. A periferia, segundo os autores da Teoria Marxista da Dependência, obedece a uma lógica de inserção diferenciada no sistema capitalista, elas são dependentes das economias hegemônicas. Para explicar essa lógica de dominação-dependência, os autores conseguiram se estabelecer como genuína Escola Latino-Americana ao desenvolveram uma metodologia própria, formulando e operacionalizando conceitos originais para explicarem o desenvolvimento econômico e as contradições do modo de produção capitalista na periferia do sistema econômico internacional. É preciso continuar acompanhando esta produção, especialmente a recente aproximação com os teóricos da Economia Política do Sistema-Mundo, logo novos artigos com pesquisa bibliográfica serão necessários.

\section{REFERÊNCIAS}

Bambirra, V. (1985). El capitalismo dependiente latino-americano. México: Siglo Xxi.

Blomström, M. e Hettne, B. (1984). Development Theory in Transition. The Dependency Debate and Beyond: Third World Responses. London: Zed books.

Bresser-Pereira, L. C. (2016). A construção política do Brasil: sociedade, economia e Estado desde a Independência. São Paulo: Editora.

Carcanholo, M. D. (2013). O atual resgate crítico da Teoria Marxista da Dependência. Trabalho, Educação e Saúde, 11(1). DoI: 10.1590/S1981-77462013000100011

Cardoso, F. H. e Serra, J. (1978). As desventuras da dialética da Dependência. Estudos CEBRAP, 23.

Dos Santos, T. (1972). Dependencia y cambio social. Santiago: CESO.

Dos Santos, T. (1978). Imperialismo y Dependencia. México: Ediciones Era.

Frank, A. G. (1973). América Latina: subdesarrollo o revolución. México: Ediciones Era.

Kay, C. (1989). Latin American Theories of Development and Underdevelopment. London: Routledge. Larrain, J. (1998). Theories of Development. Capitalism, Colonialism and Dependency. Oxford: Polity Press.

Marini, R. M. (1973). Dialéctica de la Dependencia. México: Ediciones Era.

Marini, R. M. (1979). El ciclo del capital en la economía dependiente. In U. Oswald (org.), Mercado y Dependencia. México: Nueva Imagem.

Marini, R. M. (1992). América Latina: Dependência e Integração. São Paulo: Marco Zero.

Marini, R. M. (2000). Dialética da Dependência. Petrópolis/Buenos Aires: Vozes/Clacso.

Martins, C. E. (2011). Globalização, Dependência e Neoliberalismo na América Latina. São Paulo: Boitempo.

Martins, C. E. (2017). Algumas reflexões em torno do conceito de Superexploração do Trabalho. Revista da Sociedade Brasileira de Economia Política, 48(Set/Dez).

Martins, C. E. (2018). A Teoria Marxista da Dependência à luz de Marx e do Capitalismo contemporâneo. Caderno CRH, 31(84). DOI: 10.1590/s0103-49792018000300003 
Moraes, I. A. e Vieira, F. A. C. (2015). Capitalismo agrário e movimentos campesinos no Paraguai. Estudos Históricos (Rio de Janeiro), 28(56). Dor: 10.1590/S0103-21862015000200008

Osorio, J. (2016). Sistema mundial e formas de Capitalismo: a Teoria Marxista da Dependência Revisitada / Worldwide system and the forms of Capitalism: Marxist Dependency Theory Revisited. Revista Direito e Práxis, 7(13). Dor: 10.12957/dep.2016.21820

Ouriques, N. (1994). Hacia una Teoría Marxista de la Dependencia. In R. Marini e M. Millán (orgs.), La Teoría Social Latinoamericana. Tomo II. México: El Caballito.

Palma, G. (1987). Dependencia y desarrollo: una visión crítica. In D. Seers (org.), La Teoría de la Dependencia: una revaluación crítica. México: Fondo de Cultura Económica.

Piketty, T. (2014). Capital in the Twenty-First Century. Cambridge: Harvard University Press.

Prado, F. C. (2010). História de um não-debate: a trajetória da Teoria Marxista da Dependência no Brasil. Comunicação E̊ Política, 22.

Rostow, W. W. (1978). Etapas do desenvolvimento econômico: um manifesto não comunista. Rio de Janeiro: Zahar Editores.

Wasserman, C. (2017). A Teoria da Dependência: do nacional-desenvolvimentismo ao neoliberalismo. Rio de Janeiro: FGV. 